\title{
Ethical Principles of Construction of Hospital Crisis Management System in mainland China
}

\author{
Gu Manyi \\ Research Center of Development \& Management of Sichuan Hospital, College of Humanities and \\ Management Sciences, Sichuan Medical University, Lu Zhou, Sichuan 646000, China. \\ satisfied5060@163.com,903665127@qq.com
}

Keywords: moral principles, hospital crisis management system, mainland China

\begin{abstract}
Hospital crisis management research mostly concentrates in system construction at present in mainland China. Ethical principles have existed in hospital management system. But it is very difficult to play its role in the practice of hospital crisis management. Cases around hospital crisis management system of mainland China will be collected in this research. According to the results of comparison and qualitative analysis on these cases, the research will reveal the status quo \& characteristics of ethical principles of hospital crisis management system in mainland China. The paper finds out that ethical principles of hospital crisis management system is more one-sided. In actual hospital crisis management, practice of dealing with hospital crisis is mostly not in accordance with ethics principles. According to relevant experience of crisis management, hospital uses ethical principles to deal with hospital crisis management that is more effective than mandatory law \& system. Therefore, ethical principles should be integrated into construction of hospital crisis management system.
\end{abstract}

\section{INTRODUCTION}

In recent years, a plethora of crises has drawn substantial media attention in various industry and environmental sectors. Such crises often stem from shortcomings in ethical awareness, judgment or action that allows what might have been preventable or relatively manageable problems to escalate into much more cumbersome, chronic or tragic situations (Nielsen and Dufresne, 2005; Gioia, 1995; Werhane, 1991). In fact, ethics are so central to the effective management of organizational crises that the highly respected Ethics Resource Center (ERC, 2011). Ethics and crisis management intersect in important ways. First, ethical lapses can precipitate, perpetuate or exacerbate crisis events. Second, ethics are integral to crisis management in that, regardless of the cause of the calamity, an effective resolution will involve ethical considerations (ERC, 2011; Pauchant and Mitroff, 1992; Sandin, 2009). Understanding how people attribute crisis responsibility to the organization is critical for an organization in a crisis (Seon-Kyoung An Karla K, Gower Seung Ho Cho, 2011).

\section{LITERATURE REVIEW}

Against medical corruption, it needs reshape medical humanistic spirit, and think about methods of medical market economy ethics of hospital management construction (Zheng Daxi, 2009). Matters of hospital management do not figure prominently on the medical ethics agenda. However, management decisions that have to be taken in the area of hospital care are in fact riddled with ethical questions and do have significant impact on patients, staff members, and the community being served. In this decision making process evidence based medicine (EBM) plays an increasingly important role as a tool for rationalizing as well as rationing health care resources (Biller-Andorno, N.; Lenk, C.; Leititis, J, 2004). 


\section{A. Application of Ethics in Hospital Management System}

The Confucian doctrines of benevolence, uprightness, politeness, wisdom and integrity all have greatly affected and supported the moral management of hospital (Zheng Daxi, 2008). It is an urgent ethical requirement and the chief task for hospital administrators to achieve humanistic medical service through humanistic administration of hospitals (Du Shuying, Wang Xiangping and Li Zuobing, 2007). The managers always pay more attention to "People" and 'Love' now, instead of laying stress on "Profit" and "Loss" in the past. (Tan Haitao, 2008). The ethical responsibility of services marketing in public hospital is that public hospital should be embody public interest and assume the moral responsibility to protect the interests of patients in charring out services marketing activities. (Liu Qian, etc., 2010).

\section{B. Relationship between ethics and hospital management}

Hospital administrative morals are required to overcome negative elements of socialist market economy. (Huang Weican, 1995). Hospital public relation is consistent with hospital ethics, which reflects the integration trend of management and ethics (Tan Yixiao and Li Bocong, 2010). The development of medical information means popularization of information relevant with medicine, including the information about privacy and property protection. This contradicts medical ethics and the relevant problems should be solved with the establishment of morals, systems, laws and regulations (Li Shusen etc., 2011). How to manage medical record efficiently, accurately and timely, are the medical information construction goals. Therefore, hospital must further strengthen medical record management, and ensure scientific management (Zhang Ran et al., 2012).

\section{MORAL PRINCIPALS IN CONSTRUCTION OF HOSPITAL CRISIS MANAGEMENT SYSTEM IN MAINLAND CHINA}

Ethical factors have important influence on hospital management.

A. Hospital image impact. Hospital image is constituted by the hospital medical ethics, value, service quality, and so on. Good hospital image is hospital intangible assets. Moral image is the most important factor in the hospital image.

B. Hospital benefit. To seek a good benefit (including economic and social benefits) is the basic starting point and destination of management. Ethics and Profit of modern hospital exist at the same time; they are all inclusive and mutual. By emphasizing its ethics, hospital expanded its profitability. Especially in the market competition, do not say that morality cannot maintain hospital credibility. Therefore, hospital management ethics is an important way to make hospital have a potential benefit in the long term.

C. Hospital competitiveness. With socialist market economic system gradually established, hospital has also launched an increasingly fierce competition. Hospitals want to improve competitiveness that the key is medical service quality. Quality of medical service refers to the level of medical technology, contains the level of medical ethics, and emphasizes the objectivity, impartiality, transparency and integrity.

D. Hospital cohesion influence. Harmonious relationship between cadres and workers can stimulate workers sense of pride and sense of mission hospital showed a strong cohesion; and a group consciousness. Therefore, using the moral strength to shape the hospital's team spirit, is very important to improve the hospital management level.

Influence of ethical factors of hospital crisis management function is complex, but generally speaking, there are some following basic aspects:

E. Ethical idea of hospital crisis management. Ethical concept of hospital management refers to the performance of certain moral consciousness \& cognition, which regulates the behavior of 
hospital management. Specifically include: people-oriented management concept; management philosophy; the management idea of honesty; management concept of harmony.

F. Hospital ethics spirit. Hospital ethical spirit of business activities and their own development process, combined with hospital characteristics gradually formed and trained for medical staff. This kind of group consciousness is concentrated expression of hospital development goal, belief pursue Hospital ethics can strengthen hospital personality. Hospital ethical spirit once formed that will become stable and lasting factors. It plays a role of maintaining and consolidating hospital in a certain stage of medical service and management behavior, promotes realization of hospital crisis management function.

G. Hospital administrator's moral quality. Hospital administrator's moral quality has an effect on the management function in two aspects: on the one hand, manager's moral quality is effective guarantee to promote them to complete responsibility and standard behavior. On the other hand, good moral quality of managers is spiritual power to win the appeal.

\section{CONCLUSION AND SUGGESTION}

These ethical factors have great influence on the image, benefit, competitiveness and cohesion of the hospital. Ethical management is a new management mode, which is the inevitable choice of hospital management innovation. Carrying out ethical management is the objective requirement of the mission and value of the hospital, which is very important to construct the harmonious relationship between doctors and patients, improve the operation efficiency and realize sustainable hospital development. Ethical management is modern management idea and value concept, management ethics is application of management ethics in the practice of management, is the practice of ethical management mechanism, is a real action in management. It is very important for hospital crisis management system.

\section{Acknowledgement}

Financed by: Science and Technology Department of Sichuan Province-Luzhou Municipal People's Government- Sichuan Medical University joint project of China in 2014, "Research on construction of hospital crisis management system in the perspective of dispute resolution (project number: No.: LY-17).

\section{References}

[1]Biller-Andorno, N.; Lenk, C.; Leititis, J. “Ethics, EBM, and hospital management.” Journal of Medical Ethics. Apr2004, Vol. 30 Issue 2, p136-140. 5p. DOI: 10.1136/jme.2003.007161.

[2]Chen Dezhi and Xu Ying, (2012). 'Medical Ethics Archive: a New Coordinate for Hospital Management'. Chinese Medical Ethics, 2012(1):67-70.

[3]Chen Pei, Lu Qi and Xv Shanhua. (2010). 'Ethical Management—Soul of Hospital Management in the 21th Century'. Chinese Medical Ethics, 2010(4):53-55.

[4]Ethics Resource Centre (ERC) (2011), “Accepting responsibility responsibly: corporate response in times of crisis”, A Discussion Guide for Corporate Boards and Senior Executives, available at: http://www.ethics.org/files/u5/crisisWP-Final.pdf, ERC, Arlington, VA. 4.

[5]Gu Weimin, (2000). 'Adapting Hospital Moral Construction to Development of Health Services'. Chinese Hospital Management, 2000(10):27-28.

[6]James, E.H., Wooten, L.P. and Dushek, K. (2011), “Crisis management: informing a new leadership research agenda”, The Academy of Management Annals, Vol. 5 No. 1, pp. 455-493.

[7]Liu Qian, Xiang Yueli, Fang Fang and Liu Jingfu, (2010). 'The Ethical Responsibility of Services Marketing in Public Hospital'. Medicine and Society, 2010(10):37-39.

[8]Li Shusen, Gao Chenguang and Xiang Hongmei, (2011). 'Considerations and Primary 
Discussions on Ethic Issues in Informatization Management of Hospitals'. Modern Hospital Management, 2011(2): 69-71.

[9]Li Yongsheng, (2010), "Medical corruption and hospital management ethics." Medicine \& Philosophy (Humanistic \& Social Medicine Edition), 2006(10): 12-14.

[10]Li Zhenliang, Li Xiaofeng, (2007). 'Contribution of Chinese Traditional Ethics Contribute to the Moral Management in Hospital.' Medicine \& Philosophy: Humanistic \& Social Medicine Edition, 2007(5): 36-38.

[11]Nielsen, R.P. and Dufresne, R. (2005), "Can ethical organizational character be stimulated and enabled? Upbuilding” dialog as crisis management method”, Journal of Business Ethics, Vol. 57 No. 4, pp. 311-326.

[12]Pang Yunxiu, Zhao Zengfuand and Wang Changli, (2003). 'Target of service-centerd principle of management moral in hospitals.' Chinese Medical Ethics, 2003(4):11-12.

[13]Sandin, P. (2009), “Approaches to ethics for corporate crisis management”, Journal of Business Ethics, Vol. 87 No. 1, pp. 109-116.

[14]Tan Haitao, (2008). 'On Thesis of the Ethical Principle in Hospital Management.' Journal of Shaoyang University (Social Science Edition), 2008(6):16-18.

[15]Tan Yixiao and Li Bocong, (2010). 'Thinking on the Ethics of Hospital Public Relation'. Modern Hospital Management, 2010(4):13-16.

[16]Wang Haibing, (2011). 'Relationship between the Organization Ethical Climate and the Doctors-patients Communication.' Hospital Administration Journal of Chinese People's Liberation Army, 2011(11): 1046-1048.

[17]Werhane, P. (1991), "Engineers and management: the challenge of the challenger incident", Journal of Business Ethics, Vol. 10 No. 8, pp. 605-616.

[18]Wu Caiqing, (2012). 'Research on Nursing Management with Ethical Concept.' Chinese Medical Ethics, 2012(6):781-782.

[19]Wu Zhengyi, (2008). 'Definition of public administration ethics in the field of public hospital management '. Chinese Hospital Management, 2008(11):4-6.

[20]Xie Chunyan, Huang Hai, Wang Shuyan and Shen Dongxiang, (2012). 'Ethical Thinking on Enhancing Management in Medical Safety.' Chinese Medical Ethics, 2012(1):79-80.

[21]Xu Yuanhong and Wei Fuxiang, (2004). 'Theoretical understanding of the moral dimension and the tendency of interest in the ethics of hospital management'. Jiangsu Management of Health Care, 2004(5):5-7.

[22]Zhang Ran., (2012). 'Medical Ethics Problems of Medical Record Management'. Chinese Medical Record, 2012(12): 8-9.

[23]Zhang Fang, Jia Yan and Li Zhongzhi, (2012). 'Ethical reflections on hospital human resource management'. Chinese Hospitals, 2012(10): 73-75.

[24]Zhao Yiming, etc., (2006). 'Practice and experience of hospital ethics management'. Chinese Journal of Hospital Administration, 2006(7):495-496.

[25]Zhao Zengfu et al. (2003). 'Hospital management ethics'. Military Medical Science Press, Beijing, China.

[26]Zheng Daxi, (2009). "The warning and thinking of hospital management ethics in the social transition period.” Medicine and Society, 2009(5): 19-21. 